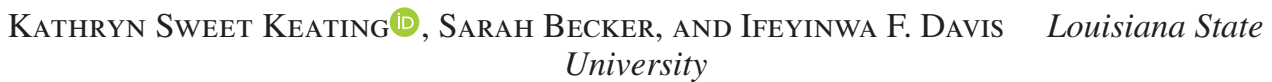

Thomas Chandler Columbia University

TIM SLACK Louisiana State University

Jaishree Beedasy Columbia University

\title{
Families Coping With Financial Loss Following the Deepwater Horizon Oil Spill
}

Objective: This study examines family strategies for coping and adaptation to social disruption from the 2010 Deepwater Horizon oil spill (DHOS) in south Louisiana.

Background: The DHOS is a technological disaster of unprecedented scale and ongoing impact, including the socioeconomic disruption of families.

Method: Using data from focus groups, grounded-theory methods informed a thematic analysis of spill-related economic loss and coping mechanisms among families in the spill-affected region.

Results: Key findings were as follows: (a) long-term economic impacts persisted but were nuanced and differed across places; (b) for families living in multistressor environments, concerns about the DHOS spilled over into other aspects of social functioning and became enmeshed with perceptions of other environmental stressors; and (c) economic exposure after the DHOS affected families differently based on social position and community social structure.

Department of Sociology, Louisiana State University, 26 Stubbs Hall, Baton Rouge, LA 70803 (keati7@1su.edu).

Key Words: conservation of resources, Deepwater Horizon oil spill, disaster resilience, family coping.
Conclusion: This study contributes to existing knowledge on technological disaster and family resilience in the face of environmental shocks and stressors, underscoring the utility of the conservation of resources model of stress in this area of research.

Implications: This research offers information about family-level response to oil spill impacts and may be of interest to policymakers and practitioners who work to support resilience in disaster contexts.

Louisiana's coastal communities are home to a vibrant blend of cultures, livelihoods, and identities (Henry \& Bankston, 2002). The State's abundant oil and gas reserves-both onshore and offshore-have supported the development of an oil and gas industry that employs workers in all 64 of its parishes (U.S. Energy Information Administration, 2019). The seafood industry is another pillar of Louisiana's economy. Commercial fishers in Louisana are among the nation's top harvesters of oysters, crabs, shrimp, and crawfish (Louisiana Department of Health, 2019). Although rich with natural and cultural resources, coastal environments and communities of Louisiana also are uniquely vulnerable to environmental hazards (Coastal Protection and Restoration Authority, 2018). 
Sociodemographic vulnerability can compound the impacts of disaster, as about one in five Louisianans lives below the poverty line. Louisiana also has one of the highest rates of poverty among children in the United States (27.4\%; U.S. Census Bureau, 2018). The National Oceanic and Atmospheric Administration estimates that communities in Louisiana have sustained more than 70 separate "billion-dollar" natural disaster events between 1980 and 2020 (National Centers for Environmental Information, 2020). The present study seeks to examine the effects of a parallel and exacerbating danger: a human-caused technological disaster, the BP Deepwater Horizon oil spill (DHOS). Here, we provide a qualitative account of family coping in the aftermath of the DHOS in coastal areas of south Louisiana.

The DHOS is the largest offshore oil spill in U.S. history. It is estimated more than 200 million gallons of oil were released into the Gulf of Mexico between the time of the initial rig explosion in April 2010 and the time it took to finally cap the wellhead 3 months later. Across the five Gulf states, more than 1,300 miles of shoreline were oiled. Because the Deepwater Horizon rig was located off the coast of south Louisiana, coastal areas of the state bore the brunt of this impact (Mississippi-Alabama SeaGrant Consortium, 2019). The resulting damage to natural ecosystems, communities, and economies warranted complex and long-term cleanup, compensation, and monitoring efforts. The disaster's economic, ecological, and social impacts continue to unfold.

As part of a larger mixed-methods study, Resilient Children, Youth, and Communities (RCYC), this analysis employed qualitative techniques to draw insights on family coping in the aftermath of the DHOS. Data were drawn from more than 9 hours of recorded conversations from focus groups with parents and primary child caregivers living in six communities across south Louisiana. The objective of this research was to obtain deeper insights into the post-spill experiences of Louisiana families as participants described strategies for coping and adaptation to the social disruption resulting from the DHOS. Our study contributes to the existing body of knowledge around human-caused disaster and family resilience in the face of environmental shocks and stressors (e.g., Arata et al., 2000; Bonanno et al., 2010; Osofsky \& Osofsky, 2018; Picou et al., 2004) by highlighting how place shapes south Louisiana parents' and child caregivers' individual and family experiences.

\section{BACKGROUND}

Disaster has been characterized for social inquiry as "the physical impacts of or problems caused for human communities by unplanned and socially disruptive events" (Kreps 1984, p. 311). Exposure to a disaster can threaten the things people value most-including social relationships, finances, and property (Arata et al., 2000; Hobfoll, 2012). Technological—or human-caused-disasters, such as the DHOS, differ from disasters that people view as "natural" in many ways. Rather than being perceived as an "act of God" beyond human control, technological disasters often result in contested narratives around disaster impacts, responsibility, and blame that spur greater social disruption due to rancorous discord, distrust, and protracted litigation (Arata et al., 2000; Baum et al., 1983; Picou et al., 1992, 2004; Ritchie, Gill, \& Long, 2018). Such contexts have been termed corrosive community (e.g., Freudenburg \& Jones, 1991; Picou et al., 2004).

Exposure to a disaster takes different forms. In the case of a technological disaster like an oil spill, people may experience direct exposure to the spill through touch or smell. Indirect exposure involves secondary contact with a disaster-affected individual, environment, or community. For example, a fisher might come into physical contact with oiled water or fish during their work (i.e., direct exposure), but that person also may experience economic disruption and social disorganization resulting from the spill (i.e., indirect exposure). Indeed, indirect exposures tend to affect much broader populations (Arata et al., 2000; Palinkas, 2012; Palinkas et al., 1993). For example, for commercial and recreational fishers in Louisiana and across the Gulf, short-term disruption of the industry after the DHOS included fishery closures and harvest bans, with longer lasting impacts related to public health concerns about safety of seafood for consumption (Carroll et al., 2016; Simon-Friedt et al., 2016). Those employed in the seafood industry, however, were not the only ones affected. Workers in the oil and gas industry were challenged with restrictions on platform work and a moratorium on drilling that halted employment in the 
months following the spill (Carroll et al., 2016). Tourism along the coast also was negatively impacted by effects to coastal environments and marine resources, making vacationing in the area less viable. For example, in Terrebonne Parish, eco/cultural tourism and recreational fishing declined dramatically; tourism in the New Orleans metropolitan area, historically supported by a robust seafood restaurant industry, also weakened (Nadeau et al., 2014).

Social structural factors can further influence disaster exposure impacts. Those who hold disadvantaged social positions before disasters are often at higher risk during the event and more affected in its aftermath (Cope \& Slack, 2017; Fatemi et al., 2017; Mohammad \& Peek, 2019; Myers et al., 2008). For instance, individuals who depend on renewable natural resources for their livelihoods (i.e., renewable resource communities or RRCs), such as fishers, are especially vulnerable to economic and psychosocial impacts after an oil spill (Arata et al., 2000; Cope \& Slack, 2017; Gill et al., 2012; Parks et al., 2018). Resilience approaches to understanding disaster recovery place a focus on the complex mechanisms by which communities, families, and individuals prepare for, cope with, and adapt to these types of stressors (e.g., Abramson et al., 2015; Gall, 2013). These ideas are rooted in ecological social system theories (Miller et al., 2010), which highlight the interdependence of nested micro, meso, and macro-level social systems that influence each other reciprocally (Boon et al., 2012; Bronfenbrenner, 1977).

At the individual level, resilience may be understood as a type of personal "hardiness" derived from characteristics that enhance one's ability to cope with and adapt to stressful situations (Bonanno, 2004). At the community level, resilience is a multidimensional concept that considers the unique blend of resources and assets that enhance a community's ability to collectively and cooperatively respond to stressors or shocks (National Academies of Sciences, Engineering, and Medicine, 2019). At the family level, resilience to disaster can be conceptualized as processes and characteristics that enable the family as a social system to prepare for, withstand, and recover from disaster impacts (Ronan et al., 2008; Walsh, 2004). Examining family resilience is critical for studies of disaster recovery. Families are among the most fundamental social units in society and the primary mechanism for the care and socialization of children.

Children are especially vulnerable to the impacts of disaster because they are nested within the family system and are dependent on adults in their lives for safety, consistency, and support (King et al., 2015; Osofsky \& Osofsky, 2018; Norris et al., 2002; Peek, 2008; Williams et al., 2008). For children, the experience of disaster also is influenced by others within their "family sphere" and neighborhood community (Fothergill \& Peek, 2015). Parents and caregivers facing a disaster must often make decisions that affect an entire household.

Because a technological disaster can generate such enduring and complex impacts, economic and social disruption may spill over into other areas of life, affecting functioning across interconnected individual, family, and community systems. Owners of family-run businesses, for example, may encounter special stresses related to the disaster as they cope with interrelated personal and professional economic disruption (Stafford et al., 2013). Research in the years following the 1989 Exxon Valdez oil spill (EVOS) yielded insight into indirect family impacts. For instance, Picou et al. (1992) found that people living in areas affected by the EVOS were more likely to report a change in relationships with family members than those living in a control community. Work disruption for individuals and family members following a technological disaster can be exacerbated by stressful litigation and compensation claims, lack of institutional trust, increased perception of risk, and perceptions of chronic community damage (Picou et al., 2004; Ritchie et al., 2013). Following the DHOS, research has connected exposure to spill-related economic loss with negative health outcomes for children in both the medium term (Beedasy et al., 2020) and long term (Slack et al., 2020).

Studies of the impact of involuntary job loss on family dynamics outside of disaster contexts also shed light on how human-caused disasters may impact families. These outcomes range from mental health challenges, such as depression, to decreases in social participation, altered fertility decisions, and marital discord (Attewell, 1999; Brand \& Burgard, 2008; Del Bono et al., 2012; Doiron \& Mendolia, 2012; Sherman, 2009). The cause of job loss may be an important consideration, as Doiron and 
Mendolia (2012) found that involuntary job loss due to redundancy (such as a plant closing) was associated with lower likelihood of marriage dissolution compared with job loss due to dismissal. With this in mind, disaster-related job loss could be less likely to cause marriage dissolution than other types of job loss.

Although loss of income or employment may be especially difficult for men who see the role of provider as central to their masculine identity, flexibility in beliefs around gender norms may enhance the capacity of individuals and families to cope with job loss in prosocial ways (Sherman, 2009). Therefore, within the disaster context, it is important to understand the role of families' beliefs about and adaptive behaviors around gender norms. Gender-adaptive coping strategies include practices such as increased acceptance of spousal employment, changes in economic power dynamics within the home, and a focus on the value of supportive, involved parenting during times of economic distress (Sherman, 2009).

Undoubtedly, the experience of both disaster and job loss are stressful events. Hobfoll's conservation of resources model (CoR) of stress suggests that individuals are motivated to obtain and protect important resources, and distress occurs when these resources are lost or threatened (Hobfoll, 1989, 1998). The CoR model identifies four resource types: objects (e.g., possessions, natural resources), personal characteristics (e.g., identity, self-esteem), life conditions (e.g., relationship quality), and energies (e.g., money, knowledge; Hobfoll, 1989). This theoretical model has been used to explain stress and trauma following a variety of experiences including both disaster (i.e., Arata et al., 2000; Binder et al., 2020; Freedy et al., 1992; Hobfoll, 2012; Palinkas et al., 1993; Ritchie, Little, \& Campbell, 2018) and changes to work-family dynamics (i.e., Grandey \& Cropanzano, 1999; Hobfoll \& Shirom, 2001; Wayne et al., 2017). In the context of oil spills specifically, Arata et al. (2000), Gill et al. (2012), and Palinkas (1993) applied the CoR model to studies of spill impacts after both the EVOS and DHOS, and Ferreira et al. (2018) used the framework to understand patterns of intimate partner violence following the DHOS. An important element of this theory is the idea that individuals may employ strategies to offset lost resources-through replacement, shifting the focus of attention away from the loss, or reevaluating resources to cope with the loss (Hobfoll, 1989).

Both resilience and CoR theories are useful concepts for connecting existing knowledge on disaster impacts with research on family dynamics. Indeed, Hobfoll (2001) tied vulnerability to CoR, identifying that "those with greater resources are less vulnerable to resource loss, [whereas] those with fewer resources are more vulnerable to resource loss and less capable of resource gain" (p. 349). These bodies of knowledge suggest that an event such as the DHOS has the potential to incite multisystemic socioeconomic impacts, and resilient individuals living in affected areas will employ strategies to offset these impacts in response to threatened or lost resources. We brought together these two theoretical frameworks to better understand the interrelationship of work-family dynamics and economic effects of oil spill exposure by examining how variations in family characteristics affect the coping strategies employed in response to threatened or lost resources.

We employed qualitative analysis of narrative data collected from six focus groups conducted in south Louisiana to explore differential impact, perceived stress, and subsequent coping within families. The focus on family systems and parent/caregiver perspectives builds on existing qualitative research conducted in spill-affected communities (e.g., Cherry et al., 2015; Gill et al., 2016; King et al., 2015) and contributes to the overall body of knowledge on family and disaster (e.g., Fothergill \& Peek, 2015; King et al., 2015; Mohammad \& Peek, 2019; Osofsky \& Osofsky, 2018; Peek, 2008; Williams et al., 2008).

\section{ObJectives}

Because resilience is a multisystemic concept that considers the interplay of characteristics across nested social systems, we first asked: How do parents/caregivers in spill-affected areas describe economic effects related to the DHOS? By exploring participants' stories across place, we can explicate connections between community-level attributes and individual experiences. Next, with a more nuanced understanding of how parents/caregivers in our focus groups characterized economic effects, we identified themes of perceived stress through a CoR lens and connected this to resilience via 
coping strategies by asking: What strategies do parents/caregivers and families in spill-affected areas use to cope with these effects?

\section{DAta AND Methods}

The qualitative data used for this analysis were collected as part of the larger RCYC project. RCYC is a longitudinal, mixed methods study that tracked long-term impact of the DHOS on families and their children from 2014 to 2018, building on findings from Columbia University's Gulf Coast Population Impact project. RCYC is a collaborative effort between Louisiana State University and Columbia University, funded by the Gulf of Mexico Research Initiative.

Focus groups are often combined with quantitative surveys in mixed methods approaches and offer the benefit of capturing both nuanced qualitative narrative data and information about interactional dynamics within a group (Cyr, 2017; Kamberelis \& Dimitriadis, 2000). Focus groups are a collectivistic approach that allow for the inclusion of multiple voices through layered narratives (Madriz, 2000). Compared with individualistic approaches, collectivistic approaches also decrease interaction between the researcher and participants while increasing interaction between the participants themselves, reducing the influence of the researcher over the process and empowering the participants to shape discussions (Madriz, 2000, p. 840).

\section{Sample and Approach}

Six focus groups were conducted in the following Louisiana parishes: Vermilion, Terrebonne, Lafourche, Plaquemines, Orleans, and St. Tammany. Portions of these parishes were identified as heavily impacted by the DHOS, and a probability sample of households with children was developed for a multiwave survey (for more details on the sampling design, see Abramson et al., 2013; Beedasy et al., 2020). In November 2017 , focus group participants were drawn from a larger sample of 484 survey participants. Focus group participants were purposively selected with the intent of capturing people in each community with a range of DHOS experiences. Recruitment for focus groups was planned with a target of approximately 10 participants per community, with a total of 46 individuals ultimately participating across the six groups.
Each focus group was facilitated by a team of three researchers: a lead facilitator, note-taker, and timekeeper. Sessions were held on weekday evenings in centrally located public venues in each community (e.g., a public library). All focus groups were audio-recorded, and sessions lasted 90 minutes on average. The lead facilitator guided the conversation using a series of preformulated open-ended questions, probing for details to responses and redirecting side conversations as necessary (Holstein \& Gubrium, 1995). Focus group participants were offered an institutional review board-approved incentive of $\$ 50$ as a token of appreciation. Table 1 shows the question guide used in each focus group.

Focus group audio recordings were transcribed, and the qualitative data from the narrative transcripts were then coded by three researchers. An initial focus group codebook was developed using the RCYC survey instrument as a guide. The survey included modules, such as "child health," "adult health," and "economic impacts," among others. These modules were based on theoretical linkages to oil spill exposure suggested by the extant literature. As such, the initial codebook included codes such as "responsible party," "personal health," "child health," "financial loss," and "career change."

With this codebook as a starting point, grounded-theory methods were first used to analyze the narrative text (Glaser \& Strauss, 1967; Strauss \& Corbin, 1998). To prepare the text for analysis, transcripts were unitized by a lead coder who identified meaningful conceptual breaks within the text (Campbell et al., 2013). Unitization ensures that all coders are working with the same units of analysis within the narrative transcripts and is especially useful for conversational transcripts without clear breaks or instances where multiple people are speaking (Campbell et al., 2013). This method also facilitates assessment of interrater reliability and the identification of passages subject to disagreements in coder interpretation.

In Stage 1 of the analysis, three researchers worked independently to code the passages from the narrative transcripts using variables in the codebook while simultaneously employing blind, open coding techniques to create new codes for emergent themes. In Stage 2, an iterative process of discussion around revisions to the initial codebook was used as new information emerged. New codes drawn from 
Table 1. Resilient Children, Youth, and Communities Focus Group Question Guide

1. In April 2010, how did you learn about the BP Deepwater Horizon oil spill, and how did you keep up with news related to the disaster?

2. In what ways were you, your children and family, and your community exposed to and/or impacted by the oil spill? (Clarify if needed: How do you think the oil spill has affected neighborhood children, families, and communities?)

3. Do you think that families and children are still experiencing problems related to the oil spill? If so, could you describe these ongoing issues?

4. Who do you think the parents turned to for help when families and children had problems related to the oil spill?

5. What role do you think social media, like Facebook and Twitter, played as a means of communication among your family, other community members, or the youth and children concerning the oil spill disaster and related issues?

6. In what ways have the needs of families and children changed (e.g., health, social services, education, and food)?

7. What do you think are the barriers to health care access? How do you think these barriers could be overcome?

8. What do you think are the barriers to social services access? How do you think these barriers could be overcome?

9. How has your community's communication with public health services, social services or local or state officials on the emerging needs of your community changed since the oil spill?

10. Was the BP compensation process an issue? If so, in what ways?

emergent themes included: "peer information," "regulation," "food insecurity," "water issues," "worker safety," "environmental damage," "emotional response," "community dynamics," "family dynamics," "leaving community," and "protective factor." (Not all codes were used in this analysis.) All transcripts were then coded using the revised codebook. Across the three researchers working to code the focus group data, interrater reliability for codes in this analysis was $99.2 \%$, calculated using a simple percent-agreement method (Stemler, 2004). In rare cases of discrepancies in coder interpretation, the group discussed the passage in an effort to reach intercoder agreement and, when necessary, undertook a revision to the codebook. All differences in initial coder agreement were resolved via this iterative process.

Thematic analysis was then used to build on the codes developed from the grounded-theory strategy described earlier (see Braun \& Clarke, 2006), with a focus on instances in which parents/caregivers in the focus groups brought up financial loss. Because the focus group component was part of a larger mixed-method study, the initial code of "financial loss" was preformulated. During the grounded-theory coding process, the "financial loss" code was applied to passages that included mention of "suffering, losing financially, or struggling to get by due to spill." From the full transcript narratives, the coding team identified 129 unique instances in which participants mentioned financial loss. It is important to note that although some focus group questions dealt directly with spill impacts and compensation processes, mentions of financial loss could be found throughout each group's conversation.

Using these 129 mentions as a starting point, passages coded as "financial loss" were then sorted by type of financial loss discussed. Seven subtypes of financial loss emerged from this analysis: loss of property values, loss related to oil and gas jobs, seafood industry loss, local business loss, loss related to costs of consumer products, and general loss. The "general loss" code was used to identify situations in which people spoke generally of spill-related financial impact that did not clearly fit into one of the other categories. (One individual also stated explicitly that they had not experienced a loss due to the DHOS; this instance was coded under the financial loss subtype "no loss.") Each of the seven financial loss subtype themes were then reviewed for coherency across sorted passages, as well as in relation to the data set as whole, to ensure saturation (Braun \& Clarke, 2006). It is important to keep in mind that the collectivistic approach of the focus group conversation allowed for layering of narratives and questioning between participants, with potential for participants' perception of loss to change through conversation with their peers.

\section{RESUlts}

\section{Place and Type of Financial Loss}

As illustrated in Figure 1, which shows the most frequently mentioned type of loss by geographic area, place mattered in discussions 
Figure 1. Major Financial Loss Themes by Community.

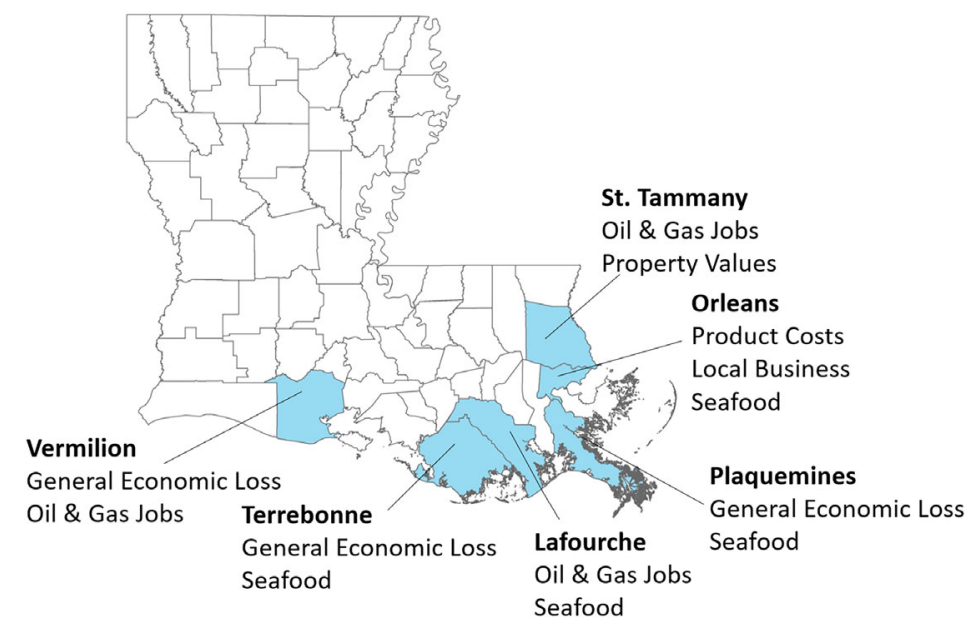

of spill-related financial loss in the years following the disaster. Here, we discuss different ways economic exposure following the DHOS affected families differently based on social position and community social structure. More specifically, structural factors in each area influenced the type of financial loss that emerged as most salient in focus groups for each community. These factors highlight the first key finding of this analysis: Nearly a decade after the spill, long-term economic impacts persisted but were nuanced and differed across place.

Property values. Discussions of DHOS financial loss related to real estate or property values and rental income varied by geographic location. Comments about property values often referenced proximity to water, citing either concerns around water quality following the spill or general mentions of vulnerability to flooding and natural disaster risk. Participants in St. Tammany Parish shared the most concerns about changes in property values as a result of the spill compared with other communities. In a group discussion around community vulnerability to both natural disasters and the DHOS, one St. Tammany participant described uncertainty around changing property values:

I knew a couple of people that live along the water, and I'm not really sure if this affects any of you or not ... they're still concerned with the oil spill that it affects the impact of their value of their land or their property. It may not be as bad now as it was like those first few years after [the DHOS], but ... those are extremely expensive houses ... they kind of felt that because of the oil coming in that their land ... would not be as sellable because they still were seeing oil.

Although losses in property value were less frequently discussed in Orleans Parish, conversations did emerge around financial loss from rental property cancellations and subsequent frustration with lack of compensation for those losses. When asked by the group facilitator about experiences with compensation for losses following the spill, two participants described the "instantaneous" impacts on waterfront rental properties and the subsequent claims process:

R1: "We had [several] vacation rental houses during the spill, everything was cancelled, all our renters cancelled that were coming. We did apply to BP, a flat denial. ... And that's our main source of income is-our rental property."

R2: "And it happened instantaneously. I saw it on the news that ..."

R1: "[It's] because they're on the water."

R2: "That night I started getting cancellation emails from everybody, people cancelled 6 months, 7 months out. So, it was just-it just went flat. And I approached BP with all of that evidence I was like, "Wow."”

Variation in concern over real estate and rental loss was likely related to higher property values 
in and around the New Orleans metropolitan area. For many who work in New Orleans, St. Tammany Parish houses several bedroom communities situated along the north shoreline of Lake Pontchartrain. Of the six study communities, St. Tammany Parish also had the highest median household income, as well as the highest average value of owner-occupied homes (U.S. Census, 2017). In Orleans Parish, with its robust tourism industry, participants with rental income felt the sting of indirect financial loss combined with the stress of unsuccessful attempts to offset the loss through compensation claims.

Both examples included specific reference to proximity of the property to water. This association of water-in this case, waterfront properties-with loss and uncertainty was a theme echoed throughout focus group conversations. For participants in St. Tammany Parish especially, the perception of waterfront property as desirable, or an indicator of social status, appeared to have been challenged in the years following the spill, exacerbated by the threat of natural disasters and other environmental stressors, such as nuisance flooding. Low-lying coastal areas are especially vulnerable to nuisance flooding, a term used to describe any flooding that "does not pose significant threat to public safety or cause major property damage but can disrupt routine day-to-day activities and place strain on infrastructure" (Moftakhari et al., 2018, p. 4218). As the St. Tammany group's discussion turned to relocation, one participant described a desire to move due to flooding, water quality concerns, and changes to her property's land-use classification:

Personally, my husband and I have been talking the last year or so, if we get a chance we're moving too. Because, it's just I'm not comfortable being out there anymore. We were constantly flooding, every time we flood, there is an oil sheen over the water everywhere. ... I can't blame it on BP, there's no telling why. The Parish marks everything as marshland now out there, because of it constantly flooding. And we don't flood from rain, we flood from tide ... they're claiming most of our land now as marshland.

Although anxieties around proximity to the water were discussed in the other communities, financial loss due to decline in property values was not a common theme outside of Orleans and St. Tammany Parishes. Compared with these two communities, the median value of owner-occupied homes was lower for Vermilion, Terrebonne, Lafourche, and Plaquemines Parishes (U.S. Census, 2017). Although the difference in property values may explain some variation in concern over spill-related losses across these communities, those situated more directly along the Gulf Coast also have faced head-on the threat of another environmental stressor - coastal land loss - for some time (Burley, 2010; Couvillion et al., 2017). It is plausible that location and long-term, ambient exposure to the threat of land loss, in addition to overall lower home values, could influence personal values and perceptions of risk or loss with regard to real estate in coastal parishes. These perceptions could also interact with feelings of attachment to family-owned property, resources such as homeowner's insurance or mortgage obligations, and property ownership versus renting. Participants who discussed property values seemed to connect experiences of DHOS impacts with other environmental stressors, such as flooding or hurricanes; however, coastal land loss was not explicitly mentioned in these conversations.

Oil and gas jobs. For participants in St. Tammany, Vermilion, and Lafourche Parishes, financial loss as a result of spill-related changes to the oil and gas industry was a major topic of discussion. Men and women impacted by losses related to oil and gas jobs shared narratives of family-level coping in response to changes in income, work availability, and industry regulations. When questioned about the overall impact of the DHOS on families, one participant in St. Tammany Parish shared her perspective as a stay-at-home parent impacted by her spouse's reduced hours:

\footnotetext{
My husband worked in the oilfield industry too, he worked for [an oil and gas company] and they started cutting off a lot of their overtime and everything like that, so, it was straight time check. He was the only one working, I'm a stay-at-home mom.
}

When conversation in Vermilion Parish turned to the impacts of the spill on work life, the group shared experiences with both the fishing and oil and gas industry. One participant described slowdowns in offshore work that affected his income as the sole breadwinner for his family:

And as far as the impact, I mean on family and stuff-I work offshore and on land, so financially, 
when the work slowed down-I'm the main source of income-your income goes down, everybody suffers from it. You do your best to kind of change things around, but you did what you had to do, you know? So, it did impact a lot.

These two passages highlight the impact that oil and gas losses had on both the individual and on gender dynamics within the family system, with examples of stressed breadwinner/homemaker roles from both perspectives. Oil and gas industry employment plays a role in the economies of all six RCYC study communities. For a variety of historical and structural reasons, the oil and gas industry in the United States has been historically classified as a "male-dominated industry" (McKee, 2014). With an average annual salary in North America of more than $\$ 70,000$ in 2019 (U.S. Bureau of Labor Statistics, 2019), individuals employed in the oil and gas industry often make well above the median income for their community. Impacts of the DHOS on oil and gas jobs represent a threat to incomes sizeable enough to support single-income households, creating stress and subsequent shifts in family dynamics. Both participants described "changing things around" to adjust to different means of securing income, relating these experiences to their identities as a homemaker and breadwinner, respectively. Nested within the family system, each individual must cope with personal role stress while also making decisions that affect the family system as a whole.

Seafood. Along the coast in Terrebonne, Plaquemines, and Lafourche Parishes, as well as in Orleans Parish, conversations about economic effects also turned to seafood. Discussions around seafood-industry losses connected environmental and economic impacts to narratives of family business and cultural values. In the Lafourche Parish focus group, the facilitator prompted members of the group to speak about their own experiences and perceptions of spill impacts on children, families, and the community. In response, the owner of a seafood business shared a story of financial loss and perceptions of ongoing challenges for other fishers in her community:

At the time we had a seafood business. And so, I mean, of course, it impacted us. People weren't going out and catching things, and so we suffered financially because, I mean, if you can't buy it, you can't sell it, and you can't fish it, and stuff like that ... and I know the shrimpers too, they were having a really difficult time with their catch the last several years.

In Terrebonne Parish, the group discussed DHOS-related fishing impacts at length. One participant described changes she had noticed in the culture around commercial fishing in her community:

\section{It's the livelihood of the area. Our culture was commercial fishing, and it would carry on down each generation. The younger generation doesn't have that anymore because it's gone because their parents had to sell what they had, so, they can find a job and make ends meet. So, it's everything. The livelihood is just not there.}

In Orleans Parish, discussions of seafood-related financial loss highlighted frustration around financial assistance processes. Some group members voiced concern for people living in rural areas outside of the city, as well as members of underrepresented groups, such as Vietnamese fishers living in the area. One participant shared:

In this community ... most of us is fishermen. We have boat, shrimp boat, fishing boat. I have commercial fishing boat ... some of them have had [help] from the oil spill, but some don't. Like me, I have none. And-I have my boat, it's a big boat. They turn me down, and I ask them for help, and they turn me down.

These conversations capture the ongoing impact of the spill and other environmental stressors on the seafood industry across RCYC parishes. These economic impacts are multifaceted, with immediate environmental and regulatory impacts followed by longer term effects on harvest and demand (Carroll et al., 2016). Indeed, many participants mentioned not only changes in market price but also fluctuations in seafood harvests, when discussing experiences of financial loss.

Compared with discussions of oil and gas loss, which sometimes referenced a return to (a more regulated) normalcy in recent years, participants who had experienced seafood-related losses described the ongoing impact and lamented cultural and trade-knowledge loss. For example, in a discussion around vulnerability and economic effects on both oil and gas and fishing, one participant in Terrebonne 
Parish described changing norms around intergenerational fishing trades and a perceived change in opportunities for youth:

[Children] were brought up that during shrimp season, the parents took them out of school, or they home-schooled them because they were out on that boat. They were learning a trade. What their dad did, their grandfather, and their grandfather and so on and so on did. And they taught their kids. So, future generations can know the old ways. It ain't like that no more.

Continuing the discussion of impacts on fishers in Terrebonne Parish, another participant shared a story that touches on the role of seafood in his own family's foodways, describing a visit from his son complicated by changes in availability of shrimp and crabs:

My son came home from overseas, I asked him, I said, "What you want me to cook you?" He said, "Daddy, all I want is a boiled crabs and boiled shrimp." So, thanks to this lovely lady right there [points to another focus group participant], her husband sold me some shrimp. So, I had shrimp, and I had crabs to give to my son. But what I used to go catch, now, I got to buy.

Seafood culture is visible and included in tourism promotion across south Louisiana. For example, Delcambre, a town situated on the border of Vermilion and neighboring Iberia Parish, is home to the annual Delcambre Shrimp Festival, nearby Morgan City hosts the annual Shrimp and Petroleum Festival, and there are numerous competitive recreational fishing events throughout the year. Participants explicitly emphasized the cultural value of the commercial seafood industry - both personally and in communities - and struggled with the challenge of maintaining or letting go of a livelihood and lifeway.

Local business and product costs. In Orleans and Terrebonne Parishes, participants discussed the spillover of economic impacts from the DHOS onto other local businesses. They shared narratives of loss or compensation experienced personally or by others in the community, such as bartenders, tax preparers, and hairdressers. Some expressed frustration and resentment around perceptions of unfair compensation payouts for people working in less visibly affected industries, evidence of "corrosive community" contexts that can emerge from protracted litigation after technological disaster (Picou et al., 2004; Ritchie, Gill, \& Long, 2018).

One participant expressed concern about financial struggles of "mom and pop" companies, as well as larger corporations in the area:

R1: "Everybody is invested in today's little companies. Mom and pop company, you might say. They're dissolving. They're finished with it."

R2: "Close the doors."

R1: "Big companies are even struggling. All of these big contracts, some of the biggest they got in the world ... economically, it really just hurt the economy. It was devastating."

The cost of additional spending on consumer products to buffer against spill-related damages was another key theme in Orleans and Plaquemines Parishes. Descriptions of increased household product costs varied, including expenses related to air quality and home repairs following the spill. In Orleans Parish, the facilitator asked the group about ongoing impacts of the DHOS on families. In the conversation that followed, two participants described making home repairs with health concerns in mind:

R1: "We had to change our [air] ducts because I couldn't put enough freshener in there and I was trying to get the smell. And then, we took up our rug just to have a floor."

R2: "Yeah, we took the rug up too, because the allergy."

In describing rug removal in their home, the second speaker mentioned concerns over allergies, echoing several other focus group discussions around product costs that highlighted concerns over out-of-pocket costs for health treatments and changes in health and wellness behaviors. This is further illustrated in the following remarks from two Orleans Parish participants:

"My son is taking allergy pills every day. He gets-he has headaches. He got sensitive skin; I have to buy sensitive products."

"I mean, it -it impacts ... everything. Like foods, you can't eat certain foods because it can-it can trigger an attack. Or trigger an allergy outbreak, or eczema ... it impacts economically all around the board." 
These conversations overlapped with other discussions around personal health and health care access and may be examples of spill-related illness anxiety (Ayer et al., 2018). Because many participants who described out-of-pocket costs also experienced uncertainty about the source of the allergy or illness, the cost of these expenses could be interpreted as both financial and emotional. Of the six RCYC communities, Orleans Parish has the lowest median income (U.S. Census, 2017). In terms of vulnerability, households with lower income stand to be disproportionally affected by these types of out-of-pocket costs. Needing to allocate limited funds-especially for childcare necessities-creates stress as caregivers weigh costs and need.

General economic loss. Although many conversations around financial loss included specific references to the preceding themes, some described more general concerns about personal or financial loss or descriptions of loss that did not clearly fit into a category. References to general economic loss were the most frequent subtheme that emerged from coding, and the top subtheme for Plaquemines and Terrebonne Parishes. Some mentions were brief, with participants interjecting conversationally with statements such as "the economy just went down." Others identified an overall reduction in the number of available jobs or described changes they had seen in their community as a result of an altered economy. When a conversation around spill-related health concerns and environmental quality in Plaquemines Parish turned to relocation, one participant shared general concerns about the economy and local youth. She empathized with the struggles of those facing few legitimate career opportunities:

They don't have nothing down here for these kids.
They could go in the lane and play. But they got
drug dealers out there. We're not hating on them
at all because some of them-some people, you
can't get a job down there because you got to know
this person, you got to know that person. Some
of them are overqualified, some underqualified.
I mean, there's just nothing. And they could put
some stuff down there for these kids. They really
could.

A participant in Terrebonne Parish expressed similar sentiments around the relationship between limited economic opportunity and crime as part of the group's larger discussion on both seafood-related losses and health in Terrebonne Parish:

And the crime rate. I mean, when you don't have a job, and you don't have money, and you don't have this, and you don't have that, people are doing whatever they have to do.

Moreover, a crabber in Terrebonne Parish shared that he had noticed persistent negative changes in cultural norms among crabbers. His words simultaneously sympathized with others' loss while expressing frustration with stealing:

That's the same thing with the crab traps and those people out there trying to make a living. They are setting 250, 300 traps out there. And there were people - they're not working and all that. They want to feed their family. I understand that. But don't go robbing somebody's crab traps. And I was always told, if you're going to take something out of somebody's trap, be nice enough to at least set it back and put it back in the water. But people nowadays, it's not like it used to be back in the old days. The old days, you go talk to the man that owns the crab traps, he'd tell you, yeah; you can run about five, six, seven traps.

When speaking of general losses, participants often referenced their community as a whole or others in their community and brought up deleterious impacts on the fabric of social ties therein, such as crime. In the preceding passages, we see evidence of the corrosive community contexts that may emerge after technological disaster, which also have been documented in communities impacted by the EVOS (Picou et al., 2004). In Plaquemines Parish, most participants referenced their community when discussing general loss - a circumstance possibly related to the size or close-knit dynamics of the community. Those who spoke of general loss at the individual or family level primarily referenced personal experiences with seeking employment or described balancing multiple jobs with family roles. Across all communities, more women than men connected general loss to family-level experiences. In Terrebonne and Plaquemines, both men and women connected general economic loss with crime. These conversations did not address perceptions of personal safety but rather shifted the focus to structural stressors, expressing sadness for others' limited opportunity and the loss of a valued sense of community and quality of community bonds. 


\section{Families Coping With Financial Loss}

Narratives of resilience through coping and adaptive mechanisms emerged organically from discussions about financial loss. Many participants reflected on immediate and long-term changes in both their personal and professional lives in response to spill-related impacts. Discussions of coping strategies were organized into three general categories: (a) coping through changes at home, (b) coping through changes at work, and (c) changing place. These categories are not mutually exclusive. Discussions around adjustments to work or home often overlap or tie into mentions of leaving the community altogether, a consideration complicated by multigenerational ties to land and trade. The following analysis focuses on coping strategies at home and work, including overlapping dynamics and tensions between these systems. The passages that follow call attention to a second key finding: for families living in multistressor environments, economic concerns about the DHOS exhibited a "spillover" into other areas of social functioning and became enmeshed with perceptions of other environmental stressors.

Coping with changes at home. Parents/ caregivers described coping with spill-related financial loss through a variety of strategies employed within the family system. Some spoke of a process of adjustment through changing family activities and relationships to cope with reduced income or increased stress. Others articulated shifts in attention to positive aspects of the experience or changes in personal value systems in the years following the spill.

Several conversations included references to the impact of stress on marital relationships, an example of threatened or lost personal conditions (Hobfoll, 1989). Both men and women described marital discord and even divorce as a result of financial loss. For example, when describing the cumulative stress of Hurricane Gustav in 2008 followed by the DHOS in 2010, a participant in Terrebonne Parish shared:

So, I had a double whammy. So, this oil spill actually impacted me financially, mentally because I went into a deep depression. My marriage was on the line. I felt worthless.... My husband and I fought like cats and dogs. We were that close to divorce.

In Vermilion Parish, the group was asked about impacts of the spill on families, and one participant shared that financial losses had contributed to marital strain immediately after the spill:

[An impact] for me also was separation that finally led to divorce because of money.

Other family-level changes involved adjusting family roles or altering expectations and values around work and financial power within the household. Several participants described navigating strain between traditional gender roles in their relationship and loss. These statements echo existing research that suggests involuntary job loss may be especially stressful for men who see the provider role as central to their masculine identity (Sherman, 2009). In St. Tammany Parish, the facilitator asked the group to reflect on family impacts. A participant described the strain of coping with a threatened breadwinner identity while working to "land on his feet" after the spill:

\footnotetext{
Just being a breadwinner and not getting up and going to work every day, that's a pride thing.... I was out of work for a little while. But other than that, just get back at it ... I landed on my feet, and better off actually, finding a better job. But it was just scary for a while not being the provider that I've always been.
}

Responding to another conversation around family impacts, a participant in Vermilion Parish expressed sensitivity to the emotional toll of a family members' job loss. She described her attempts to modify interactions between members of her household in an effort to shift focus from the loss:

Not that you walk on eggshells, but you kind of watch what you say and what you ask for and what you do, because I know it's not their fault.

For some, financial loss prompted adjustments in family recreational activities in an effort conserve resources. Adjusting to economic changes following the spill, a participant in Vermilion Parish described reevaluating the "pros and cons" of necessary household costs versus family recreation:

We couldn't go places we wanted to go, because we were afraid - you had to say, okay — you might have wanted to go on a little vacation you did every year, but you couldn't go because of the gas prices. 
And you had to weight that against something else you needed, like if you needed, I don't know, maybe a new refrigerator or air-conditioner or something, you had to weigh your pros and cons in that kind of way, with the economy the way it was.

In Vermilion Parish, the group discussed impacts on community and family, and one participant expressed perceptions of communitywide financial loss, taking a similar shift in focus onto the role of community support in buffering the impact of financial loss for families:

Like these men here ... and other people, other families that were hurt by it, because of the lack of money, the lack-you know, everything went down-that's when we all get together, the churches, I mean the people itself, we come together and help each other.

Coping with changes at work. While some coping strategies were employed by individuals and their families at home, parents/caregivers also described changes at work. In many cases, participants related work impacts to family impacts, indicating a spillover effect between the work and family systems. Parents/caregivers described working harder or more flexibly in an effort to offset or replace lost resources associated with the financial impacts of the spill. This involved a variety of strategies-from balancing multiple jobs or increased commutes to altering work activities, selling equipment, or pursuing skills or training for new careers.

In Plaquemines Parish, limited job availability was central to discussions around general economic loss, and the group discussed changes they would like to see in their community. Several people expressed a desire for local job growth. Agreeing with this sentiment, one participant described the strain of balancing encroaching time commitments for her job commute with highly valued time spent with her children:

I drive an hour and 20 minutes a day to one job. When I get off of that job, I got to come and travel 30 minutes more to the next job. When I get home, my kids are in bed sleeping. I hardly get time with them. Like talking about it, when we do see each other, it's like we done seen Jesus, when we finally get a day with each other.

Another participant in Plaquemines echoed her sentiment:
A lot of women down here, they got two or three jobs. That's how they're trying to do it. That's the only way it's going to happen for you to move forward and have something better for your children, set them up, is for to have two or three jobs. Some people have four.

Both passages speak to strain between attempts to replace lost monetary resources through balancing multiple jobs while seeking to achieve a high-quality parent-child relationship. For these participants, conserving conditional resources such as quality relationships are weighed against other types of resources.

When asked about the ongoing impacts of the spill on children and families, one participant in Vermilion Parish described an attempt to replace lost income through piecing together odd jobs and coming to terms with adjusted expectations of work. He described a turn to "different ends" to stay financially afloat, leveraging his carpentry skills. He connected his own experiences to perceptions of others' experiences in his community:

A lot of people trying to find different ends to maybe meet their bills. Some people went to carpentry. I've done that before, I mean I just had to go do a little carpentry, make some of the ends meet. Or go cut some grass, stuff like that. Little odds and ends jobs.

Implicit in this statement is the presence of community or professional connections capable of facilitating informal jobs. Individuals with strong networks and social capital are often better positioned to leverage these relationships to piece together side jobs, orchestrating resource gain following loss (Hobfoll, 2001; Nelson \& Smith, 1999). This statement also connects with a previously discussed passage in which a Vermilion Parish participant expressed belief in the ability of community connectedness to support families facing loss through "coming together to help each other."

While some participants navigated loss by juggling multiple jobs or shifting focus, others buffered losses differently. In Terrebonne Parish, where diminishing job opportunities and seafood-related losses were central concerns, a participant shared the difficult decision she made to pawn shrimping equipment so that she could purchase necessities for her infant during fishing closures. She went on to describe the 
impact of this decision on her work once the season reopened:

\begin{abstract}
We actually had to take all of our tools and pawn them just for diapers and baby formula.... The tools that we used was actually like the pullies and all of that, the wenches and all of that was on the shrimp boat to pull up everything. So, when the season was finally open, we had no pullies, no wenches. So, we was pulling everything in by hand until we could make that money back to get the pully. Still, to this day, we do not have wenches or pullies on our shrimp boat.
\end{abstract}

Ultimately these experiences led her and her spouse to actions that indicate a reevaluation of resources-training for a new career and diversion from the culturally significant livelihood they had both grown up with in Terrebonne Parish:

\begin{abstract}
The trawling business is not doing good. Me and my husband have went back to school. We got our GED diploma. We're now in college.... We have to turn to this because the shrimping and the oystering and all of that is no good for us. We have to actually look for higher quality things that don't really meet our necessary lifestyle that we're used to $\ldots$ the bayou life.
\end{abstract}

This passage highlights adaptation and the role of resource conservation strategies in facilitating resilience: This participant did not return to baseline functioning after the disruption of the spill; instead, she landed in an adapted, reevaluated role. According to this passage, she also appeared to be in a partnered, heteronormative relationship, a factor that may have placed her in an advantaged social position relative to others who may possess different relationship characteristics.

Many parents/caregivers connected their motivation to undertake changes in work to a personal commitment to their own role as a parent/provider and a desire for positive outcomes for their children. These sentiments can be found throughout many of the passages outlined earlier, but also in the following brief expressions from parents/caregivers:

"That's the only thing. The will to go on for my kids."

"I might have to hang upside down on a light pole just to get the money to go get things I need for my kids."

\section{DisCUSSION}

Using data from six focus groups conducted with parents and caregivers living in areas of south Louisiana affected by the DHOS, this study explored how people who bear primary responsibility for children characterized economic loss across place and described subsequent coping mechanisms. Grounded-theory coding techniques informed a thematic analysis, yielding a range of financial loss types and family coping strategies for navigating spill-related social disruption.

The findings presented here build on the extant literature on technological disasters, stress, and family functioning within coupled human-environment systems in several ways. First, this analysis lends support to the idea that economic effects in the years following the spill are nuanced, persistent, and differ across place, expanding and recontextualizing existing understandings of family-level disruption, such as those produced following the EVOS (e.g., Picou, 1992). Eight years after the onset of the DHOS, many focus group participants and their families still felt indirect impacts from the spill, a finding consistent with previous literature on long-term social disruption following human-caused technological disasters (e.g., Arata et al., 2000; Baum et al., 1983; Picou et al., 2004; Ritchie et al., 2018-1). Second, for families living in environments that present multiple stressors, economic effects of the DHOS appear to exhibit "spillover" into other areas of social functioning, becoming enmeshed with perceptions of other acute and ambient environmental stressors. Although conversations about economic loss often addressed spill-specific damage to natural ecosystems, many participants also expressed concerns about the effects of the DHOS combined with other environmental stressors-including both acute natural disasters such as hurricanes, as well as lower impact threats such as nuisance flooding. Third, indirect exposure and toxic community dynamics after the DHOS have affected families differently based on social position and community social structure. Focus group conversations provided place-specific, magnified details to support existing theory and research around the social impacts of human-caused disaster, and especially indirect exposure via economic effects and toxic community dynamics (Arata et al., 2000; Cope \& Slack 2017; Dyer, 1993; Gill et al., 2012; Palinkas et al., 1993; Parks 
et al., 2018; Picou et al., 2004; Ritchie, Gill, \& Long, 2018).

Finally, these findings underscore the utility of the CoR model to understand long-term changes in individual and family-level coping in response to the enduring impacts of technological disasters (Arata et al., 2000; Gill et al., 2012; Gill et al., 2016; Hobfoll, 2012; Palinkas et al., 1993; Palinkas 2012; Ritchie et al., 2018-2). Parents/caregivers across the focus groups employed a variety of strategies to cope with individual and family-level impacts of financial loss after the spill. Both emotion- and problem-focused strategies facilitated adaptive capacity, thus enhancing resilience. We see examples of participants coping with lost or threatened resources across all categories identified by Hobfoll (1989): objective resources such as belongings; conditions such as relationship quality; personal characteristics such as role identity; and energies in the form of money or trade-knowledge valuable to future generations. Hobfoll (2001) connected the CoR model with social vulnerability, suggesting that individuals with more resources are "less vulnerable to resource loss and more capable of orchestrating resource gain" (p. 349). Indeed, narratives shared throughout the focus groups demonstrate the salience of relationships between vulnerability, resource conservation, and resilience.

\section{Limitations}

Although a strength of the qualitative approach used here is the rich detail it generated on people's oil spill experiences, a limitation is that the findings cannot necessarily be generalized beyond our focus group participants. Moreover, we do not know the degree to which selectivity bias influenced the sample of people who ultimately participated in the focus groups. This limitation may be particularly relevant in small, close-knit communities, given the potential for the emergence of contested narratives, distrust, and blame following technological disasters (see Picou et al., 2004; Ritchie et al., 2013). Although the focus groups were implemented with "family-friendly" logistics in mind (i.e., held on weekday evenings in centrally located public venues with children welcomed), access to resources such as time, childcare, and transportation could have presented barriers to participation. We also know that myriad forms of social marginalization can influence who does and does not participate in the research process. Finally, a key limitation of any collectivist approach to data collection is the potential for one, or several, individuals within the observed group to unduly influence the opinions and dynamics within the group as a whole (Stewart \& Shamdasani, 2015). However, this limitation must be weighed against strengths of such methods. Focus groups, in particular, may empower participants to shape discussions and also allow for large amounts of data to be gathered in a limited period of time, including information about interactional dynamics in conversation (Madriz, 2000).

\section{Implications}

Almost a decade after the onset of the DHOS, individuals, families, and communities continue to build their lives along the coast of south Louisiana. Thriving in a place vulnerable to environmental hazards requires personal hardiness, flexibility, access to resources, and social support (Abramson et al., 2015; Bonanno, 2004; Hobfoll, 2001; Osofsky \& Osofsky, 2018; Slack et al., in press). From a policy and practice standpoint, this study provides important insights into family-level responses to the unique economic and social impacts of oil spills. Policymakers interested in supporting resilient coastal communities in Louisiana must consider the long-term, enmeshed impacts of the DHOS with other environmental stressors on populations characterized by different social characteristics, as well as the interconnectedness of individual, family, and community systems. In addition, findings from this study underscore the relationship between socioeconomic vulnerability, resilience, and access to resources before, during, and after disaster. As such, our results support the development of policies and interventions that mitigate economic exposure to disaster through direct support to households-both in the immediate aftermath and the long-term following an event such as an oil spill.

The DHOS presented complicated and wide-ranging economic impacts to coastal communities in Louisiana (Carroll et al., 2016; Nadeau et al., 2014). Long after the initial spill incident, parents and caregivers in impacted areas often found themselves working to buffer the impact of social disruption and financial loss. Service providers involved in direct work 
with parents, caregivers, and family groups should consider the potential for such dynamics to be relevant in the lives of clients in both the immediate and long term. To this end, the development of psychosocial assessment and intervention tools intended for use in communities vulnerable to such hazards should take into consideration the unique impacts of technological disasters compared with other disaster types. Further, such experiences should be considered within the larger context of cumulative disaster exposure and adversity (Mohammad \& Peek, 2019; Osofsky \& Osofsky, 2018).

Focus group participants in this study shared a variety of emotion- and problem-focused strategies to adapt to disruption from the spill. In direct practice, narratives that explore the use of adaptive coping strategies may be elevated in collaborative conversation as examples of "strengths and resources" to support the development of richer appreciation for personal capacity (Madsen, 2007) as one element of a strengths-based approach to supporting personal resilience (Bonanno, 2004).

\section{Conclusion}

For several decades, sociological research on disaster has explored questions about social organization in response to unplanned disruption (e.g., Kreps, 1984). Resilience approaches to understanding social response to disaster have generally sought to highlight the contours of human capacity for adaptation in the face of such events to better inform planning, recovery, and response. To this end, the present study offers a nuanced characterization of family-level coping in response to spill-related economic disruption through parents' and caregivers' conversations around financial loss. Key findings contribute to existing bodies of knowledge on technological disaster-specifically the DHOS-and family resilience, underscoring the utility of the $\mathrm{CoR}$ model in understanding such dynamics. For parents and caregivers of children living in spill-impacted areas of south Louisiana, long-term economic impacts persisted for years but are nuanced and differ across place. Families experienced disruption from the DHOS differently based on social position and community social structure. Finally, for families living in environments with multiple stressors, concerns about the DHOS spilled over into other aspects of social functioning and became enmeshed with perceptions of other environmental stressors.

\section{Author Note}

This research was made possible by a grant from The Gulf of Mexico Research Initiative. Data are publicly available through the Gulf of Mexico Research Initiative Information \& Data Cooperative (GRIIDC) at https://data .gulfresearchinitiative.org (doi:10.7266/n7-nv37-sm89). Special thanks to the focus group participants in the RCYC study whose willingness to share hours of reciprocal conversation made this analysis possible.

\section{REFERENCES}

Abramson, D. M., Grattan, L. M., Mayer, B., Colten, C. E., Arosemena, F. A., Bedimo-Rung, A., \& Lichtveld, M. (2015). The resilience activation framework: A conceptual model of how access to social resources promotes adaptation and rapid recovery in post-disaster settings. Journal of Behavioral Health Services \& Research, 42(1), 42-57. https://doi.org/10.1007/s11414-0149410-2

Abramson, D. M., Peek, L. A., Redlener, I. E., Beedasy, J., Aguilar, T., Sury, J., Banister, A. N., \& May, R. (2013). Children's health after the oil spill: A four-state study. National Center for Disaster Preparedness, Columbia University. https://doi .org/10.7916/D8WQ0C4P

Arata, C. M., Picou, J. S., Johnson, G. D., \& McNally, T. S. (2000). Coping with technological disaster: An application of the conservation of resources model to the Exxon Valdez oil spill. Journal of Traumatic Stress, 13(1), 23-39. https://doi.org/10 .1023/A:1007764729337

Attewell, P. (1999). The impact of family on job displacement and recovery. The Annals of the American Academy of Political and Social Science, 562(1), 66-82. https://doi.org/10.1177/ 000271629956200105

Ayer, L., Engel, C., Parker, A., Seelam, R., \& Ramchand, R. (2018). Behavioral health of Gulf coast Residents 6 years after the Deepwater Horizon oil spill: The role of trauma history. Disaster Medicine and Public Health Preparedness, 13(3), 497-503. https://doi.org/10.1017/dmp.2018.84

Baum, A., Fleming, R., \& Davidson, L. M. (1983). Natural disaster and technological catastrophe. Environment and Behavior, 15(3), 333-354. https://doi.org/10.1177/0013916583153004

Beedasy, J., Petkova, E. P., Lackner, S., \& Sury, J. (2020). Gulf Coast parents speak: Children's health in the aftermath of the Deepwater Horizon oil spill. Environmental Hazards. Advance online publication. https://doi.org/10.1080/17477891 .2020 .1772188 
Binder, S. B., Ritchie, L. A., Bender, R., Thiel, A., Baker, C. K, Badillo, E., Goodfellow, S., Kulp, B., \& Weir, P. (2020). Limbo: the unintended consequences of home buyout programmes on peripheral communities. Environmental Hazards. Advance online publication. https://doi.org/ 10.1080/17477891.2020.1714537

Bonanno, G. A. (2004). Loss, trauma, and human resilience: Have we underestimated the human capacity to thrive after extremely aversive events? American Psychologist, 59(1), 20-28. https://doi .org/10.1037/0003-066X.59.1.20

Bonanno, G. A., Brewin, C. R., Kaniasty, K. \& La Greca, A. M. (2010). Weighing the costs of disaster: Consequences, risks, and resilience in individuals, families, and communities. Psychological Science in the Public Interest, 11(1), 1-49. https:// doi.org/10.1177/1529100610387086

Boon, H. J., Cottrell, A., King, D., Stevenson, R., \& Millar, J. (2012). Bronfenbrenner's bioecological theory for modelling community resilience to natural disasters. Natural Hazards, 60(2), 381-408. https://doi.org/10.1007/s11069-011-0021-4

Brand, J. E., \& Burgard, S. A. (2008). Job displacement and social participation over the lifecourse: Findings for a cohort of joiners. Social Forces, 87(1), 211-242. https://doi.org/10.1353/ sof.0.0083

Braun, V., \& Clarke, V. (2006). Using thematic analysis in psychology. Qualitative Research in Psychology, 3(2), 77-101. https://doi.org/10 .1191/1478088706qp063oa

Bronfenbrenner, U. (1977). Toward an experimental ecology of human development. American Psychologist, 32(7), 513-531. https://doi.org/10 .1037/0003-066X.32.7.513

Burley, D. M. (2010). Losing ground: Identity and land loss in coastal Louisiana. University Press of Mississippi.

Campbell, J. L., Quincy, C., Osserman, J., \& Pedersen, O. K. (2013). Coding in-depth semistructured interviews: Problems of unitization and intercoder reliability and agreement. Sociological Methods \& Research, 42(3), 294-320. https://doi.org/10 .1177/0049124113500475

Carroll, M., Gentner, B., Larkin, S., Quigley, K., Perlot, N., Dehner, L., \& Kroetz, A. (2016). An analysis of the impacts of the Deepwater Horizon oil spill on the Gulf of Mexico seafood industry (Report No. BOEM 2016-020). U.S. Department of the Interior, Bureau of Ocean Energy Management, Gulf of Mexico OCS Region, New Orleans, LA.

Cherry, K. E., Lyon, B. A., Marks, L. D., Nezat, P. F., Adamek, R., Walsh, S. D., Fitzgerald, K. B., Anbinder, D. R., \& Bernacchio, C. V. (2015). After the BP Deepwater Horizon oil spill: Financial and health concerns among coastal residents and commercial fishers. Current Psychology, 34(3),
576-586. https://doi.org/10.1007/s12144-0159372-4

Coastal Protection and Restoration Authority. (2018). What's at stake. http://coastal.la.gov/whats-atstake/

Cope, M. R., \& Slack, T. (2017). Emplaced social vulnerability to technological disasters: Southeast Louisiana and the BP Deepwater Horizon oil spill. Population \& Environment, 38(3), 217-241. https://doi.org/10.1007/s11111-016-0257-8

Couvillion, B. R., Beck, H., Schoolmaster, D., \& Fischer, M. (2017). Land area change in coastal Louisiana 1932 to 2016: U.S. Geological Survey Scientific Investigations Map 3381, 16. https://doi .org/10.3133/sim 3381

Cyr, J. (2017). The unique utility of focus groups for mixed-methods research. PS: Political Science \& Politics, 50(4), 1038-1042. https://doi.org/10 .1017/S104909651700124X

Del Bono, E., Weber, A., \& Winter-Ebmer, R. (2012). Clash of career and family: Fertility decisions after job displacement. Journal of the European Economic Association, 10(4), 659-683. https://doi .org/10.1111/j.1542-4774.2012.01074.x

Doiron, D., \& Mendolia, S. (2012). The impact of job loss on family dissolution. Journal of Population Economics, 25(1), 367-398. https://doi.org/ 10.1007/s00148-010-0353-5

Dyer, C. L. (1993). Tradition loss as secondary disaster: Long-term cultural impacts of the Exxon Valdez oil spill. Sociological Spectrum, 13(1), 65-88. https://doi.org/10.1080/02732173.1993 .9982017

Esri. (2017). USA Counties [Fig. 1 base map]. Sources: Esri, TomTom, U.S. Department of Commerce, U.S. Census Bureau. https://services. arcgis.com/P3ePLMYs2RVChkJx/arcgis/rest/serv ices/USA_Counties/FeatureServer

Fatemi, F., Ardalan, A., Aguirre, B., Mansouri, N., \& Mohammadfam, I. (2017). Social vulnerability indicators in disasters: Findings from a systematic review. International Journal of Disaster Risk Reduction, 22, 219-227. https://doi.org/10.1016/j .ijdrr.2016.09.006

Ferreira, R. J., Buttell, F., \& Elmhurst, K. (2018). The Deepwater Horizon oil spill: Resilience and growth in the aftermath of postdisaster intimate partner violence. Journal of Family Social Work, 21(1), 22-44. https://doi.org/10.1080/10522158 .2017 .1402531

Fothergill, A., \& Peek, L. (2015). Children of Katrina. University of Texas Press.

Freedy, J. R., Shaw, D. L., Jarrell, M. P., \& Masters, C. R. (1992). Towards an understanding of the psychological impact of natural disasters: An application of the conservation of resources Stress model. Journal of Traumatic Stress, 5(3), 441-454. https://doi.org/10.1007/BF00977238 
Freudenburg, W. R., \& Jones, T. R. (1991). Attitudes and stress in the presence of technological risk: A test of the Supreme Court hypothesis. Social Forces, 69(4),1143-1168. https://doi.org/10.1093/ sf/69.4.1143

Gall, M. (2013). From social vulnerability to resilience: Measuring the progress toward disaster and risk reduction. Interdisciplinary Security Connections, 13. https://doi.org/10.13140/2.1.2949 .4568

Gill, D. A., Picou, J. S., \& Ritchie, L. A. (2012). The Exxon Valdez and BP oil spills: A comparison of initial social and psychological impacts. American Behavioral Scientist, 56(1), 3-23. https://doi.org/ 10.1177/0002764211408585

Gill, D. A., Ritchie, L. A., \& Picou, J. S. (2016). Sociocultural and psychosocial impacts of the Exxon Valdez oil spill: Twenty-four years of research in Cordova, Alaska. The Extractive Industries and Society, 3(4), 1105-1116. https:// doi.org/10.1016/j.exis.2016.09.004

Glaser, B. G., \& Strauss, A. (1967). The discovery of grounded theory: Strategies for qualitative research. Aldine Publishing Co.

Grandey, A. A., \& Cropanzano, R. (1999). The conservation of resources model applied to work-family conflict and strain. Journal of Vocational Behavior, 54(2), 350-370. https://doi.org/ 10.1006/jvbe.1998.1666

Henry, J. M., \& Bankston, C. L. (2002). Blue collar Bayou: Louisiana Cajuns in the New Economy of Ethnicity. Praeger.

Hobfoll, S. E. (1989). Conservation of resources. A new attempt at conceptualizing stress. The American Psychologist, 44(3), 513-524. https://doi.org/ 10.1037//0003-066x.44.3.513

Hobfoll, S. E. (1998). Stress, culture, and community: The psychology and philosophy of stress. Springer.

Hobfoll, S. E. (2001). The influence of culture, community, and the Nested-Self in the Stress Process: Advancing Conservation of Resources theory. Applied Psychology, 50(3), 337-370. https:// doi.org/10.1111/1464-0597.00062

Hobfoll, S. E. (2012). Conservation of resources and disaster in cultural context: The caravans and passageways for resources. Psychiatry: Interpersonal \& Biological Processes, 75(3), 227-232. https:// doi.org/10.1521/psyc.2012.75.3.227

Hobfoll, S. E., \& Shirom, A. (2001). Conservation of resources theory: Applications to stress and management in the workplace. In R. T. Golembiewski (Ed.), Handbook of organizational behavior (pp. 57-80). Marcel Dekker.

Holstein, J. A., \& Gubrium, J. F. (1995). The active interview. Sage Publications. https://doi.org/10 $.4135 / 9781412986120$

Kamberelis, G., \& Dimitriadis, G. (2000). Focus groups: Strategic articulations of pedagogy, politics, and inquiry. In N. K. Denzin \& Y. S. Lincoln
(Eds.), Handbook of qualitative research (2nd ed., pp. 887-907). Sage Publications.

King, L. S., Osofsky, J. D., Osofsky, H. J., Weems, C. F., Hansel, T. C., \& Fassnacht, G. M. (2015). Perceptions of trauma and loss among children and adolescents exposed to disasters a mixed-methods study. Current Psychology, 34(3), 524-536. https://doi.org/10.1007/s12144-015-9348-4

Kreps, G. A. (1984). Sociological inquiry and disaster research. Annual Review of Sociology, 10, 309-330. https://doi.org/10.1146/annurev.so.10 .080184 .001521

Louisiana Department of Health. (2019). Eat safe Louisiana: Commercial seafood. http://ldh.la.gov/ index.cfm/page/444

Madriz, E. (2000). Focus groups in feminist research. In N. K. Denzin \& Y. S. Lincoln (Eds.), Handbook of qualitative research (2nd ed., pp. 835-850). Sage Publications.

Madsen, W. C. (2007). Collaborative therapy with multi-stressed families (2nd ed.). Guilford Press.

McKee, L. E. (2014). Women in American energy: De-feminizing poverty in the oil and gas industries. Journal of International Women's Studies, 15(1), $167-178$.

Miller, F. Osbahr, H., Boyd, E., Thomalla, F., Bharwani, S., Ziervogel, G., Walker, B., Birkmann, J., van der Leeuw, S., Rockström, J., Hinkel, J., Downing, T., Folke, C., \& Nelson, D. (2010). Resilience and vulnerability: Complementary or conflicting concepts? Ecology and Society, 15(3), 1-25. https://doi.org/10.5751/ES-03378-150311

Mississippi-Alabama SeaGrant Consortium. (2019). Where did the oil go? A Deepwater Horizon fact sheet. masgc.org/oilscience/where.did.oil.go .factsheet.pdf

Moftakhari, H. R., AghaKouchak, A., Sanders, B. F., Allaire, M., \& Matthew, R. A. (2018). What is nuisance flooding? Defining and monitoring an emerging challenge. Water Resources Research, 54(7), 4218-4227. https://doi.org/10 .1029/2018WR022828

Mohammad, L., \& Peek, L. (2019). Exposure outliers: Children, mothers, and cumulative disaster exposure in Louisiana. Journal of Family Strengths, 19(1): 4 .

Myers, C. A., Slack, T., Singelmann, J. (2008) Social vulnerability and migration in the wake of disaster: The case of Hurricanes Katrina and Rita. Population and Environment, 29(6), 271-291. https://doi .org/10.1007/s11111-008-0072-y

Nadeau, L., Kaplan, M., Sands, M., Moore, K., \& Goodhue, C. (2014). Assessing the impacts of the Deepwater Horizon oil spill on tourism in the Gulf of Mexico region (Report No. BOEM 2014-661). U.S. Department of the Interior, Bureau of Ocean Energy Management, Gulf of Mexico OCS Region, New Orleans, LA. 
National Academies of Sciences, Engineering, and Medicine. (2019). Building and measuring community resilience: Actions for communities and the Gulf Research Program. National Academies Press. https://doi.org/10.17226/25383

National Centers for Environmental Information, National Oceanic and Atmospheric Administration. (2020). U.S. billion-dollar weather and climate disasters. https://www.ncdc.noaa.gov/ billions/

Nelson, M. K., \& Smith, J. (1999). Working hard and making do: Surviving in small town America. University of California Press.

Norris, F. H., Friedman, M. J., Watson, P. J., Byrne, C. M., Diaz, E. \& Kaniasty, K. (2002). 60,000 disaster victims speak: Part I. An empirical review of the empirical literature, 1981-2001. Psychiatry, 65(3), 207-260. https://doi.org/10.1521/psyc.65.3 .207 .20173

Osofsky, J. D., \& Osofsky, H. J. (2018). Challenges in building child and family resilience after disasters. Journal of Family Social Work, 21(2), 115-128. https://doi.org/10.1080/10522158.2018.1427644

Parks, V., Drakeford, L., Cope, M. R., \& Slack, T. (2018). Disruption of routine behaviors following the Deepwater Horizon oil spill. Society \& Natural Resources, 31(3), 277-290. https://doi.org/10 $.1080 / 08941920.2017 .1377794$

Palinkas, L. A. (2012). A conceptual framework for understanding the mental health impacts of oil spills: Lessons from the Exxon Valdez oil spill. Psychiatry: Interpersonal \& Biological Processes, 75(3), 203-222. https://doi.org/10.1521/ psyc.2012.75.3.203

Palinkas, L. A., Downs, M. A., Petterson, J., \& Russell, J. (1993). Social, cultural, and psychological impacts of the Exxon Valdez oil spill. Human Organization, 52(1), 1. https://doi.org/10.17730/ humo.52.1.162688w475154m34

Peek, L. (2008). Children and disasters: Understanding vulnerability, developing capacities, and promoting resilience-An introduction. Children Youth and Environments, 18(1), 1-29.

Picou, J. S., \& Gill, D. A., Dyer, C. L., \& Curry, E. W. (1992). Disruption and stress in an Alaskan fishing community: Initial and continuing impacts of the Exxon Valdez oil spill. Industrial Crisis Quarterly, 6(3), 235-257. https://doi.org/10.1177/ 108602669200600305

Picou, J. S., Marshall, B. K., \& Gill, D. A. (2004). Disaster, litigation, and the corrosive community. Social Forces, 82(4), 1493-1522. https://doi.org/ 10.1353/sof.2004.0091

Ritchie, L. A., Gill, D. A., \& Farnham, C. N. (2013). Recreancy revisited: Beliefs about institutional failure following the Exxon Valdez oil spill. Society and Natural Resources, 26(6),655-671. https://doi .org/10.1080/08941920.2012.690066
Ritchie, L. A., Gill, D. A., \& Long, M. A. (2018) Mitigating litigating: An examination of psychosocial impacts of compensation processes associated with the 2010 BP Deepwater Horizon oil spill. Risk Analysis, 38(8), 1656-1671. https://doi.org/ 10.1111/risa.12969

Ritchie, L. A., Little, J., \& Campbell, N. M. (2018). Resource loss and psychosocial stress in the aftermath of the 2008 TVA coal ash spill. International Journal of Mass Emergencies and Disasters, 36(2), 179-207.

Ronan, K. R., Crellin, K., Johnston, D. M., Finnis, K., Paton D., \& Becker, J. (2008). Promoting child and family resilience to disasters: Effects, interventions, and prevention effectiveness. Children Youth and Environments, 18(1), 332-353.

Sherman, J. (2009). Bend to avoid breaking: Job loss, gender norms, and family stability in rural America. Social Problems, 56(4), 599-620. https://doi .org/10.1525/sp.2009.56.4.599

Simon-Friedt, B. R., Howard, J. L., Wilson, M. J., Gauthe, D., Bogen, D., Nguyen, D., Frahm, E., \& Wickliffe, J. K. (2016). Louisiana residents' self-reported lack of information following the Deepwater Horizon oil spill: Effects on seafood consumption and risk perception. Journal of Environmental Management, 180, 526-537. https://doi .org/10.1016/j.jenvman.2016.05.030

Slack, T., Beedasy, J., Chandler, T., Keating, K. S., Sury, J., \& Brooks, J. (in press). Family resilience following the Deepwater Horizon oil spill: Theory and evidence. In A. W. Harrist \& M. Stout (Eds.), Resilience and the community: How to build resilient communities and how communities build resilient families. Springer.

Slack, T., Kroeger, R. A., Stroope, S., Keating, K. S., Sury, J., Brooks, J., Chandler, T. \& Beedasy, J. (2020). Deepwater Horizon oil spill exposure and child health: A longitudinal analysis. Population and Environment. Advance online publication. https://doi.org/10.1007/s11111-020-00354-6

Slack, T., Myers, C. A., Singelmann, J., \& Doucet, J. M. (2010). Impacts and activities following disaster: Narratives on recovery in hurricane-affected communities. International Journal of Mass Emergencies \& Disasters, 28(1), 1-32.

Stafford, K., Danes, S. M., \& Haynes, G. W. (2013). Long-term family firm survival and growth considering owning family adaptive capacity and federal disaster assistance receipt. Journal of Family Business Strategy, 4(3), 188-200. https://doi.org/ 10.1016/j.jfbs.2013.06.002

Stemler, S. E. (2004). A comparison of consensus, consistency, and measurement approaches to estimating interrater reliability. Practical Assessment, Research \& Evaluation, 9(4), 1-11. https://doi .org/10.7275/96jp-xz07 
Stewart, D. W., \& Shamdasani, P. N. (2015). Focus groups: theory and practice (3rd ed.). Sage Publications.

Strauss, A., and Corbin, J. (1998). Basics of qualitative research: Techniques and procedures for developing grounded theory (2nd ed,). Sage Publications.

U.S. Bureau of Labor Statistics. (2019). Oil and gas extraction: NAICS 211. https://www.bls.gov/ iag/tgs/iag211.htm

U.S. Census Bureau; American Community Survey. (2018). 2014-2018 American community survey 5-year estimates: Poverty status in the last 12 months; TableID: S1701. Generated using https:// www.data.census.gov

U.S. Census Bureau; American Community Survey. (2017). 2013-2017 American community survey 5-year estimates: Selected housing and economic characteristics; TableID: DP04, DP03. Generated using https://www.data.census.gov
U.S. Energy Information Administration. (2019). Louisiana state profile and energy estimates. https://www.eia.gov/state/analysis.php?sid=LA\#1

Walsh, F. (2004). Family resilience: A framework for clinical practice. Family Process, 42(1), 1-18. https://doi.org/10.1111/j.1545-5300.2003.00001.x

Wayne, S. J., Lemmon, G., Hoobler, J. M., Cheung, G. W., \& Wilson, M. S. (2017). The ripple effect: A spillover model of the detrimental impact of work-family conflict on job success. Journal of Organizational Behavior, 38(6), 876-894. https:// doi.org/10.1002/job.2174

Williams, R., Alexander, D. A., Bolsover, D., \& Bakke, F. K. (2008). Children, resilience and disasters: Recent evidence that should influence a model of psychosocial care. Current Opinion in Psychiatry, 21(4), 338-344. https://doi.org/10.1097/YCO $.0 \mathrm{~b} 013 \mathrm{e} 328305 \mathrm{~b} 6 \mathrm{e} 4$ 